\title{
Межфразное распределение хлоридных комплексов родия (III), рутения (III) в экстракционных системах на основе жидких анионообменников
}

\author{
Симонова Т.Н., Гонтарь Е.С. \\ Донецкий национальный университет, Донецฺк
}

Поступила в редакцию 27.05.2017 г.

\begin{abstract}
Методами экстракции, молекулярной абсорбционной спектрофотометрии, ИКспектроскопии, электронной микроскопии, эмиссионного спектрального анализа с индуктивносвязанной плазмой изучено межфазное распределение ассоциатов хлоридных комплексов родия(III), рутения(III) с жидкими анионообменниками в хлороформе. Установлены закономерности, связывающие строение и свойства первичных алкиламинов $\mathrm{C}_{12}-\mathrm{C}_{18}$, разнорадикальных третичных алкиламинов с их способностью экстрагировать $\left[\mathrm{RhCl}_{6}\right]^{3-},\left[\mathrm{RuCl}_{6}\right]^{3-}$.

Ключевые слова: экстракция, хлоридные комплексы родия(III), рутения(III), жидкие анионообменники, первичные алкиламины $\mathrm{C}_{12}-\mathrm{C}_{18}$, разнорадикальные третичные алкиламины.

\section{Interphase distribution of chloride complexes of rhody (III), ruthenia (III) in extraction systems based on liquid anion exchangers}

\author{
Simonova T.N., Gontar E.S. \\ Donetsk National University, Donetsk
}

The interphase distribution of associates of chloride complexes of Rhodium (III), Ruthenium (III) with liquid anion exchangers in chloroform has been studied by spectrophotometry, inductively coupled plasma optical emission spectrometry. The regularities of construction and properties of primary alkylamynes with normal construction $\left(\mathrm{C}_{12}-\mathrm{C}_{18}\right)$, multiradical tertiary amines influence on their ability to extract highlycharged complexes of Rhodium (III), Ruthenium (III) from concentrated chloride solutions. Decrease in the volume of tertiary alkylamine radicals by substitution of two alkylamines for methyl compounds allows to reduce steric effects and use heterogeneous tertiary alkylamines such as dimethyl n-dodecylammonium to extract highly charged complexes of Rhodium (III), Ruthenium (III). The outer-sphere mechanism of extraction of high-charge complexes of Rhodium (III), Ruthenium (III) and composition of the extracted associate Rhodium (III) is determined by molecular spectrophotometry, IR spectroscopy, chemical analysis of saturated organic phase, molar ratios.

Keywords: extraction, chloride complexes of Rhodium (III), Ruthenium (III), liquid anion exchangers, primary alkylamines $\mathrm{C}_{12}-\mathrm{C}_{18}$, hetero-radical tertiary alkylamines.

\section{Введение}

Устойчивость экстрагированных солями алкиламинов соединений определяется энергией образования ассоциата (U), которая в соответствии с формулой $\mathrm{U}=\mathrm{E}_{\mathrm{g}}+\mathrm{E}_{\mathrm{c}}$ складывается из энергии, способствующей ассоциации ионов $\mathrm{E}_{\mathrm{g}}$ и энергии пространственных взаимодействий радикалов $\mathrm{E}_{\mathrm{c}}$. $\mathrm{E}_{\mathrm{g}}$ включает все виды энергии, способствующие образованию ионных пар - энергию электростатического взаимо- 
действия ионов, энергию водородной связи и др. Электронейтральные ассоциаты не образуются, когда энергия пространственных взаимодействий радикалов превышает энергию $\mathrm{E}_{\mathrm{g}}[1]$.

На извлечение и разделение простых и комплексных анионов оказывают значительное влияние величина заряда ацидокомплекса, тип координации лиганда, сольватация, стерические др. факторы $[1,2]$. Изучение распределения разнозарядных хлоридных комплексов платиновых и др. металлов с экстрагентами различных структур позволяет учитывать тонкие различия их экстракционного поведения и прогнозировать новые экстрагенты для извлечения высокозарядных ацидокомплексов (BЗА).

Катионы платиновых металлов образуют с хлорид-ионами разнозарядные ацидокомплексы, включая высокозарядные $\left[\mathrm{RhCl}_{6}\right]^{3-},\left[\mathrm{RuCl}_{6}\right]^{3-}[3,4]$. Состояние родия (III), рутения (III) в концентрированных растворах кислот в виде ВЗА является доминирующими при разложении проб, содержащих платиновые металлы [4].

В литературе имеется ряд работ, посвященных экстракции родия (III), рутения (III) азотсодержащими экстрагентами $[5,6]$. При извлечении платиновых металлов экстрагентами различных структур наблюдаются различия в их экстракционном поведении в зависимости от концентрации соляной кислоты. Независимо от ее концентрации лучше всего извлекаются хлоридами четвертичных аммониевых оснований (ЧАО) или три-н-октиламмония (TOA) платина (IV), платина (II) и палладий (II), что позволяет проводить их отделение от сопутствующих металлов. Родий (III), рутений (III), иридий (III) при прочих равных условиях переходят в органическую фазу с низкими коэффициентами распределения. Различное экстракционное поведение платиновых металлов связывают с их способностью образовывать в концентрированных хлоридных растворах разнозарядные ацидокомплексы. Извлечение $\left[\mathrm{PtCl}_{6}\right]^{2-}$, $\left[\mathrm{PdCl}_{4}\right]^{2-}$ солями третичных аминов наблюдается в широком интервале концентраций $\mathrm{HCl}\left(0.1-6\right.$ моль/дм $\left.{ }^{3}\right)$ в отличие от $\left[\mathrm{RhCl}_{6}\right]^{3-}$, который не экстрагируется уже при $\mathrm{C}(\mathrm{HCl})>4$ моль/дм ${ }^{3}[7]$. Это используется в аналитической практике для разделения платиновых металлов. Соли первичных алкиламинов с ВЗА родия (III), рутения (III) образуют устойчивые ассоциаты. Механизм экстракции высокозарядных хлоридных комплексов $\left[\mathrm{RhCl}_{6}\right]^{3-},\left[\mathrm{RuCl}_{6}\right]^{3-}$ мало изучен; считается, что из-за высокого заряда комплексные анионы $\left[\mathrm{RhCl}_{6}\right]^{3-},\left[\mathrm{RuCl}_{6}\right]^{3-}$ не экстрагируются третичными алкиламинами и др. экстрагентами. Нами показано, что высокозарядные хлоридные комплексы родия (III) и рутения (III) экстрагируются разнорадикальными алкиламинами [8].

Цель исследования - изучение закономерностей, связывающих строение и свойства первичных алкиламинов нормального строения $\mathrm{C}_{12}-\mathrm{C}_{18}$, разнорадикальных третичных алкиламинов в хлороформе с их способностью извлекать ВЗА родия (III) и рутения (III) из хлоридных растворов.

\section{Эксперимент}

Для экстракции применяли 0.1 моль/дм ${ }^{3}$ растворы аминов в органических растворителях. Содержание в н-додециламине основного вещества составило 98\%, три-н-октиламин фирмы «Fluka» содержал 95\% основного вещества. Дополнительно определяли содержание основного вещества титрованием спиртовых растворов аминов соляной кислотой с индикатором нейтральным красным. При экстракции амины переводили в солевую форму встряхиванием в делительной воронке равных объемов 0.1 моль/дм ${ }^{3}$ раствора органического основания в растворителе с 1 моль/дм ${ }^{3}$ раствором соответствующей кислоты. Хлороформ применяли реактивной чистоты. Стандартный раствор родия (Ш) готовили растворением 0.3156 г $\mathrm{K}_{3} \mathrm{RhCl}_{6}$ в растворе $\mathrm{HCl}$ с концентрацией 1 моль/дм и разбавляли этой же кислотой до объема $100 \mathrm{~cm}^{3}$. Стан- 
дартный раствор рутения (IV) готовили растворением 0,2220 г гидроксохлорида рутения в $20 \mathrm{~cm}^{3}$ раствора $\mathrm{HCl}$ с концентрацией 3 моль/дм ${ }^{3}$ и разбавляли этим же раствором кислоты до $100 \mathrm{~cm}^{3}$. Хлоридные комплексы рутения (Ш) получали кипячением раствора рутения (IV) в 10 моль/дм ${ }^{3}$ растворе соляной кислоты в течение 9 часов. Содержание металлов в водной и органической фазах контролировали фотометрическим методом, атомно-эмиссионным методом с индуктивно связанной плазмой. Фотометрическое определение проводили на колориметре концентрационном КФК-3, атомно-эмиссионное определение - на атомно-эмиссионном спектрометре с индуктивно связанной плазмой IRIS Intrepid II XDL, в котором для регистрации спектра используются оптическая схема Эшелле и полупроводниковый CID детектор. Bce измерения на спектрометре IRIS Intrepid II XDL проводили по отношению к внутреннему стандарту, в качестве которого выбран скандий.

Структуру ассоциата родия (III) с н-додециламмонием исследовали методом электронной микроскопии. Микрофотографии получали с помощью модернизированного электронного микроскопа ЭМ-125К, используя увеличение 16000-30000. Все работы по приготовлению образцов с целью устранения минимального загрязнения проводили в боксе ламинарии фирмы JOUAN (Франция). Спектры поглощения записывали на спектрофотометре «Scinco» серии S-2100 с диодноматричным детектором. ИК-спектры записывали на спектрометре Specord-75 IR. Кислотность раствора контролировали иономером И-160МИ со стеклянным электродом. Исследования проводили при температуре $20 \pm 2^{\circ} \mathrm{C}$.

\section{Обсуждение результатов}

Исследования влияния структуры органических оснований на экстракцию $\left[\mathrm{RhCl}_{6}\right]^{3-},\left[\mathrm{RuCl}_{6}\right]^{3-}$ проводили в условиях образования их в водной фазе [9-10]. Экстракцию родия (III) и рутения (III) проводили из 6 моль/дм ${ }^{3}$ и 10 моль/дм ${ }^{3}$ растворов $\mathrm{HCl}$ соответственно, соотношение водной и органической фаз составляло 1:1, концентрация родия (III) и рутения (III) -0.002 моль/дм ${ }^{3}$. В качестве экстрагентов применяли 0.1 моль/дм ${ }^{3}$ растворы хлоридов н-додециламина и три-н-октиламина в хлороформе. Выбор н-додециламина обусловлен тем, что он является наиболее эффективным экстрагентом ВЗА, а три-н-октиламин часто применяется в технологической и аналитической практике для разделения платиновых металлов. Предварительными опытами установлено, что равновесие в системе достигается в течение 15 минут. В этих условиях хлоридные комплексы Rh (III) эффективно экстрагируются хлоридом н-додециламмония $(\mathrm{R}=88 \%)$. Извлечение $\left[\mathrm{RhCl}_{6}\right]^{3-}$ хлоридом н-додециламина наблюдается также из менее агрессивных растворов, содержащих 6 моль/дм ${ }^{3} \mathrm{LiCl}$ и 1 моль/дм ${ }^{3} \mathrm{HCl}$.

Для подтверждения состава анионной части экстрагируемых ассоциатов родия (III) и рутения (III) проведены спектрофотометрические исследования. В спектрах поглощения экстрагируемого соединения родия наблюдаются два максимума поглощения при длинах волн 412 и 518 нм, которые совпадают с максимумами поглощения координационно насыщенного комплекса $\left[\mathrm{RhCl}_{6}\right]^{3-}$ в водной фазе (рис. 1) $[3,4]$. В спектрах поглощения экстрактов хлоридных комплексов рутения (Ш) наблюдается максимум поглощения при длине волны 355 нм, характерный для трехзарядного аниона $\left[\mathrm{RuCl}_{6}\right]^{3-}$ (рис. 2) [3]. Увеличение оптической плотности хлоридных комплексов родия (Ш) и рутения (Ш) в органической фазе, по-видимому, обусловлено повышением их устойчивости при взаимодействии с органическим катионом.

Образование экстрагируемых соединений хлоридных комплексов родия (Ш), рутения (Ш) с жидкими анионообменниками может протекать по реакциям ионного обмена, комплексов внедрения или по ряду одновременно протекающих этих реак-

Симонова и др. / Сорбционные и хроматографические процессы. 2017. Т. 17. № 4 
ций [11-13]. Состав экстрагируемых ассоциатов на примере родия (Ш) изучали методами молярных отношений, химического анализа насыщенной органической фазы, ИК-спектроскопии.

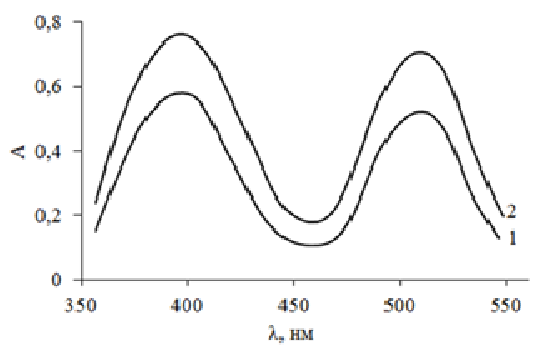

Рис. 1. Спектры поглощения $\left[\mathrm{RhCl}_{6}\right]^{3-}$ в водной (1) и органической (2) фазах

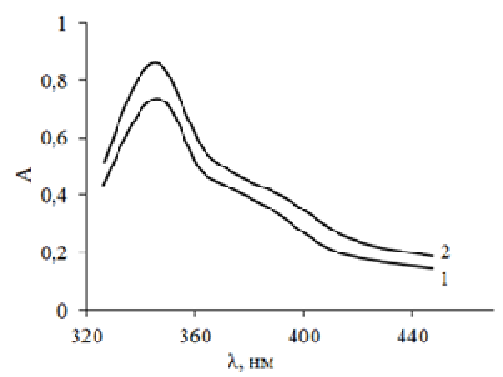

Рис. 2. Спектры поглощения хлоридных комплексов рутения (Ш) в водной (1) и органической (2) фазах

Изучено влияние концентрации алкиламмониевого катиона на степень извлечения родия (Ш) из 6 моль/дм ${ }^{3}$ раствора $\mathrm{HCl}$. При концентрации родия (III), равной 0.002 моль/дм ${ }^{3}$, максимальная степень извлечения аналита наблюдается при мольном соотношении $\left[\mathrm{RNH}_{3}{ }^{+}\right]:\left[\mathrm{Rh}^{3+}\right]=3: 1$. Экстрагируемый ассоциат $\mathrm{Rh}(\mathrm{III})$ в хлороформе отличается высокой устойчивостью. Разбавление в 100 раз не привело к изменению оптической плотности экстракта. Для изучения состава экстрагируемого ассоциата определено соотношение компонентов в насыщенной органической фазе (табл. 1). Насыщенную органическую фазу получали последовательным контактированием экстракта со свежими порциями водной фазы. Содержание родия определяли фотометрическим методом со $\mathrm{SnCl}_{2}$, хлорид-ионов- аргентометрическим методом, ндодециламина - титриметрически с индикатором нейтральным красным. В органической фазе соотношение н-додециламин : катион родия : хлорид-ион равно 3:1:6. Этому соотношению соответствует простейшая формула ассоциата $\left(\mathrm{C}_{12} \mathrm{H}_{25} \mathrm{NH}_{3}\right)_{3}\left[\mathrm{RhCl}_{6}\right]$.

Таблица 1. Анализ насыщенной органической фазы

\begin{tabular}{|c|c|}
\hline Компоненты & Содержание, моль/дм $^{3}$ \\
\hline Додециламин & 0.100 \\
\hline Родий (Ш) & 0.033 \\
\hline Хлориды & 0.198 \\
\hline
\end{tabular}

Таким образом, совокупность представленных экспериментальных результатов свидетельствует о том, что извлечение родия (III) из хлоридных растворов характеризуется переходом в органическую фазу ионного ассоциата $\left(\mathrm{C}_{12} \mathrm{H}_{25} \mathrm{NH}_{3}\right)_{3}\left[\mathrm{RhCl}_{6}\right]$, а реакция экстракции может быть описана уравнением: $3 \mathrm{C}_{12} \mathrm{H}_{25} \mathrm{NH}_{3} \mathrm{Cl}_{(\mathrm{O})}+\mathrm{RhCl}_{6}{ }^{3-} \leftrightarrow\left(\mathrm{C}_{12} \mathrm{H}_{25} \mathrm{NH}_{3}\right)_{3}\left[\mathrm{RhCl}_{6}\right]_{(\mathrm{O})}+3 \mathrm{Cl}^{-}$. Аналогичный состав установлен для хлоридного комплекса рутения (Ш): $\left(\mathrm{C}_{12} \mathrm{H}_{25} \mathrm{NH}_{3}\right)_{3}\left[\mathrm{RuCl}_{6}\right]$. ИК-спектры поглощения экстрактов подтверждают образование комплекса по механизму анионного обмена. В ИК-спектрах экстрактов родия (Ш) наблюдаются полосы поглощения $1500 \mathrm{~cm}^{-1}$ и $1585 \mathrm{~cm}^{-1}$, характерные для алкиламмониевого катиона, и отсутствуют деформационные $\left(1620 \mathrm{~cm}^{-1}\right.$ ) и валентные (3380 и $3450 \mathrm{~cm}^{-1}$ ) полосы $\mathrm{NH}_{2}$-группы. В пользу экстракции ВЗА родия (Ш) по механизму анионного обмена свидетельствует тот факт, что экстракция протекает из 6 моль/дм ${ }^{3}$ раствора $\mathrm{HCl}$, где амин находится в протонированной форме. 
Изучение структуры экстрагируемого соединения $\left(\mathrm{C}_{12} \mathrm{H}_{25} \mathrm{NH}_{3}\right)_{3}\left[\mathrm{RhCl}_{6}\right]$ проводили методом электронной микроскопии с помощью модернизированного микроскопа ЭМ-125К и компьютерного анализа полученных снимков. Вещество гомогенизировали до порошковидного состояния, готовили $10 \%$ суспензию, разбавляя в физиологические растворы. В отдельных случаях, для получения высококачественных снимков готовили «перфорированные» плёнки-подложки, которые укрепляли на опорных сетках 300mesh. Наносили препарат на плёнку-подложку капельным способом. Контрастирования препаратов не проводили. На рис. 3 приведены электронные микрофотографии ассоциата родия (Ш) с н-додециламмонием без напыления. При обычной просвечивающей электронной микроскопии происходило разрушение вещества. Для устранения данных проблем, с целью укрепления образцов использовали методику легкого косого оттенения (напыления) препаратов хромом с использованием вакуумного универсального поста (ВУП-5). На рис. 4 представлены электронные микрофотографии ассоциата родия (Ш) с н-додециламмонием с напылением. Структура экстрагируемого соединения $\left(\mathrm{C}_{12} \mathrm{H}_{25} \mathrm{NH}_{3}\right)_{3}\left[\mathrm{RhCl}_{6}\right]$ представляет собой образование крупных агрегатов неправильной формы.
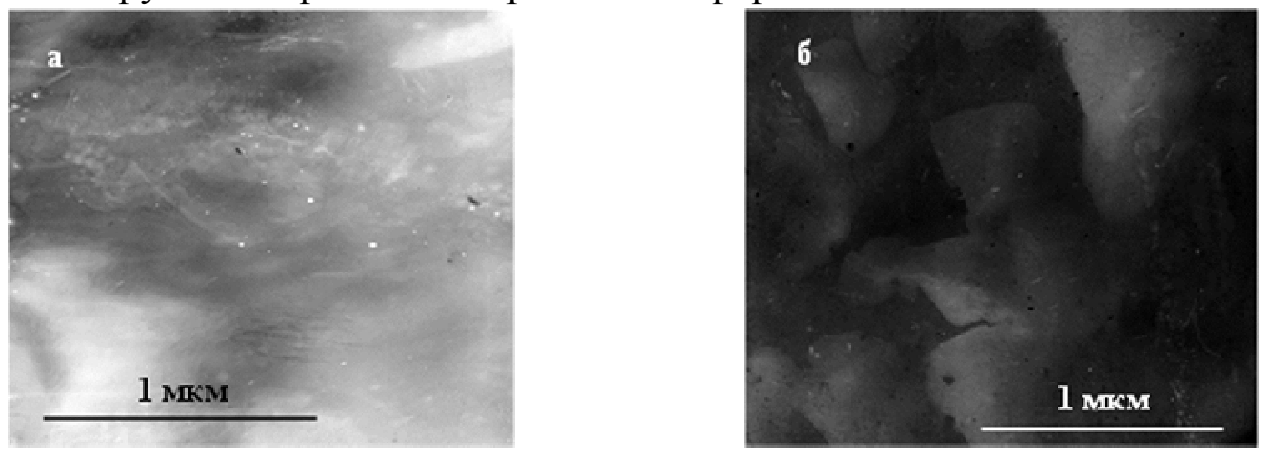

Рис. 3. Электронные микрофотографии без напыления. Проекционное увеличение $30000\left(\mathrm{a}-\left(\mathrm{C}_{12} \mathrm{H}_{25} \mathrm{NH}_{3}\right)_{3} \mathrm{Cl}\right.$; б - $\left.\left(\mathrm{C}_{12} \mathrm{H}_{25} \mathrm{NH}_{3}\right)_{3}\left[\mathrm{RhCl}_{6}\right]\right)$
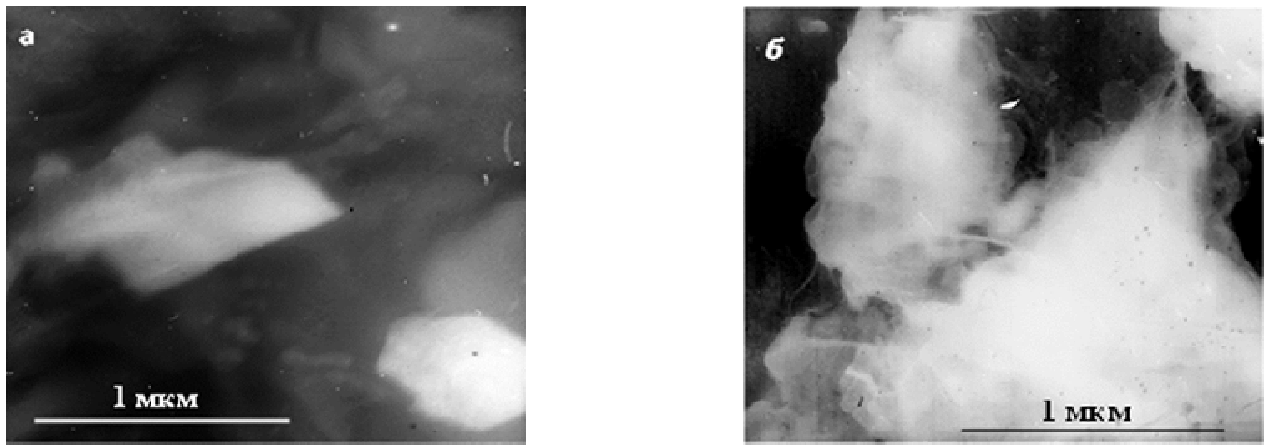

Рис. 4. Электронные микрофотографии с напылением. Проекционное увеличение $30000\left(\mathrm{a}-\left(\mathrm{C}_{12} \mathrm{H}_{25} \mathrm{NH}_{3}\right)_{3} \mathrm{Cl} ; \sigma-\left(\mathrm{C}_{12} \mathrm{H}_{25} \mathrm{NH}_{3}\right)_{3}\left[\mathrm{RhCl}_{6}\right]\right)$

При извлечении разнозарядных ацидокомплексов платиновых металлов из концентрированных хлоридных растворов не наблюдается конкуренции со стороны хлорид-ионов. Это является основой для экстракционного отделения платиновых металлов от менее устойчивых ацидокомплексов, например, серебра и др. элементов платиновой группы. Первичные алкиламины эффективно экстрагируют двух- и трехзарядные ацидокомплексы платиновых металлов (табл. 2). Содержание платиновых металлов в водной фазе определяли атомно-эмиссионным методом с индуктивно связанной плазмой.

Третичные алкиламины типа три-н-октиламина, наиболее часто применяемые для экстракции платиновых металлов, экстрагируют $\left[\mathrm{PtCl}_{4}\right]^{2-}$ на $89 \%$, плохо экстрагируют ВЗА родия (Ш) и рутения (Ш) в связи с возникновением пространственных 
затруднений при образовании ассоциата $(\mathrm{R}=5 ; 9 \%)$. Уменьшение объема радикалов третичных алкиламинов путем замены двух алкилрадикалов на метильные позволяет снизить стерические эффекты и использовать для извлечения ВЗА родия (Ш) и рутения (Ш) с сосредоточенным зарядом разнорадикальные третичные алкиламины типа диметил-н-додециламина, ранее до наших исследований не применяемые для этих целей (табл. 3). По сравнению с хлоридами ТОА, трибензиламина хлорид диметил-ндодециламмония экстрагирует В3А Rh (III) в большей степени. Спектр поглощения ассоциата $\mathrm{Rh}$ (III) с диметил-н-додециламмонием аналогичен спектру поглощения с н-додециламмонием.

Таблица 2. Экстракция хлоридных комплексов платиновых металлов алкиламинами различных структур $\left(\mathrm{C}_{\mathrm{Me}}{ }^{\mathrm{n}+}=10^{-4}\right.$ моль/дм ${ }^{3}, \mathrm{C}(\mathrm{LiCl})=6$ моль/дм ${ }^{3}, \mathrm{C}(\mathrm{HCl})=1$ моль/дм $\left.{ }^{3}\right)$

Экстракционный реагент: 0.1 М раствор хлорида $\quad$ Степень извлечения, $\mathrm{R} \%$ \begin{tabular}{l|c|c|c|}
\cline { 2 - 4 } алкиламина в хлороформе & $\mathrm{PtCl}_{4}{ }^{2-}$ & $\mathrm{RhCl}_{6}{ }^{3-}$ & $\mathrm{RuCl}_{6}{ }^{3-}$ \\
\cline { 2 - 4 }
\end{tabular} н-додециламмоний три-н-октиламмоний

\begin{tabular}{c|c|c|}
98 & 88 & 99 \\
\hline 89 & 5 & 9
\end{tabular}

Таблица 3. Влияние структуры органических оснований на экстракцию хлоридных комплексов $\left[\mathrm{RhCl}_{6}\right]^{3-}\left(\mathrm{C}\left(\mathrm{Rh}(\mathrm{III})=2 \cdot 10^{-3}\right.\right.$ моль $/$ дм $^{3}, \mathrm{C}(\mathrm{HCl})=6$ моль $/$ дм $\left.^{3}\right)$

\begin{tabular}{|c|c|}
\hline $\begin{array}{c}\text { Экстракционный реагент: } 0.1 \text { М раствор } \\
\text { хлорида алкиламина в хлороформе }\end{array}$ & $\mathrm{R}, \%$ \\
\hline додециламмоний & 88 \\
\hline диметил-н-додециламмоний & 70 \\
\hline три-н-октиламмоний & 5 \\
\hline трибензиламмоний & 3 \\
\hline
\end{tabular}

Таким образом, разнорадикальные третичные алкиламины с одним длинным и двумя короткими алкилрадикалами можно использовать для извлечения ВЗА родия (III), рутения (III). Применение экстракции разнорадикальными органическими основаниями к водным растворам, где существуют разнозарядные ацидокомплексы, в том числе и высокозарядные, позволяет сдвигать равновесие в сторону образования определенных форм и прогнозировать новые экстрагенты для извлечения высокозарядных анионных комплексов.

\section{Заключение}

Методами спектроскопии, химического анализа установлен состав экстрагируемых ассоциатов $\left(\mathrm{C}_{12} \mathrm{H}_{25} \mathrm{NH}_{3}\right)_{3} \mathrm{RhCl}_{3},\left(\mathrm{C}_{12} \mathrm{H}_{25} \mathrm{NH}_{3}\right)_{3} \mathrm{RuCl}_{3}$ в хлороформе по механизму анионного обмена. Электронные микрофотографии ассоциата родия (III) c Hдодециламмонием с напылением показали образование крупных агрегатов неправильной формы. Уменьшение объема радикалов третичных алкиламинов путем замены двух алкилрадикалов на метильные позволяет снизить стерические факторы и использовать для извлечения ВЗА родия (III), рутения (III) с сосредоточенным зарядом разнорадикальные третичные алкиламины типа диметил-н-додециламмония, раннее не применяемые для этих целей.

\section{Список литературы}

1. Шевчук И.А. Экстракция органическими основаниями. Киев. Вища школа. 1978. $172 \mathrm{c}$.
2. Шевчук И.А., Симонова Т.Н. Экстракция соединений цветных и редких металлов из карбонатных, серусодержащих и галоге- 
нидных растворов. Донецк. ДонГУ. 1999. 215 c.

3. Гинзбург С.И. и др. Аналитическая химия платиновых металлов. М. Наука.1972. $613 \mathrm{c}$.

4. Золотов Ю.А., Варшал Г.М., Иванов В.М. Аналитическая химия металлов платиновой группы: Сб. обзорных статей. М. Едиториал УРСС. 2003. 592 с.

5. Kolekar S.S., Anuse M.A. // Talanta. 2002. Vol. 58. pp. 761-771.

6. Jaree A., Khunphkdee N. // J. Ind. Eng. Chem. 2011. Vol. 17. pp. 243-247.

7. Khattak M.A., Magee R.J. // Anal. Chim. Acta. 1969. Vol. 45. pp. 297-304.

\section{References}

1. Shevchuk I.A. Jekstrakcija organicheskimi osnovanijami, Kiev, Vishha shkola, 1978, $172 \mathrm{p}$.

2. Shevchuk I.A., Simonova T.N. Jekstrakcija soedinenij cvetnyh i redkih metallov iz karbonatnyh, serusoderzhashhih i galogenidnyh rastvorov, Donetsk, DonGU, 1999, 215 p.

3. Ginzburg S.I. et al. Analiticheskaja himija platinovyh metallov. M., Nauka, 1972, 613 p.

4. Zolotov Yu.A., Varshal G.M., Ivanov V.M. Analiticheskaja himija metallov platinovoj gruppy: Sb. obzornyh statej. Moscow, Editorial URSS, 2003, 592 p.

5. Kolekar S.S., Anuse M.A., Talanta, 2002, Vol. 58, pp. 761-771. DOI: 10.1016/S00399140(02)00365-X.

6. Jaree A., Khunphkdee N., J. Ind. Eng. Chem., 2011, Vol. 17, pp. 243-247. DOI: 10.1016/j.jiec.2011.02.013.

Симонова Тамара Николаевна - к.х.н., доцент кафедры аналитической химии, Донецкий национальный университет, г. Донецк

Гонтарь Елена Сергеевна - к.Х.н., научный сотрудник кафедры аналитической химии, Донецкий национальный университет, г. Донецк
8. Шевчук И.А., Симонова Т.Н., Гонтарь Е.С. // Украинский химический журнал. 2006. T. 72. № 9. С. 29-33.

9. Бусько Е.А., Бурков К.А., Калинин С.К. // Журнал аналитической химии. 1970. Т. 25. №5. C. 958-977.

10.Башилов А.В., Кузьмин Н.М., Нестеров А.А., Рунов В.К. // Журнал неорганической химии. 2000. Т. 45. №4. С. 743-751.

11.Шмидт В.С. Экстракция аминами. М. Атомиздат. 1980. 264 с.

12.Гиндин Л.М. Экстракционные процессы и их применение. М. Наука. 1984. 144 с.

13. Меретуков М.А. Процессы жидкостной экстракции в цветной металлургии. М. Металлургия. 1985. 222 с.

7. Khattak M.A., Magee R.J., Anal. Chim. Acta, 1969, Vol. 45, pp. 297-304. DOI: 10.1016/S0003-2670(01)95601-6.

8. Shevchuk I.A., Simonova T.N., Gontar E.S., Ukrainian Chemistry Journal, 2006, Vol. 72, № 9, pp. 29-33.

9. Busko E.A., Burkov K.A., Kalinin S.K., J. of Analytical Chemistry, 1970, Vol. 25, No. 5, pp. 958-977.

10. Bashilov A.V., Kuz'min N.M., Nesterov A.A., Runov V.K., Russian Journal of Inorganic Chemistry, 2000, Vol. 45, No. 4, pp. 743-751.

11. Shmidt V.S. Jekstrakcija aminami. M., Atomizdat, 1980, $264 \mathrm{p}$.

12. Gindin L.M. Jekstrakcionnye processy i ih primenenie. M., Nauka, 1984, 144 p.

13. Meretukov M.A. Processy zhidkostnoj jekstrakcii v cvetnoj metallurgii. M., Metallurgija, 1985, $222 \mathrm{p}$.

Simonova Tamara N. - Ph.D. (chemistry), associate professor, department of analytical chemistry, Donetsk National University, Donetsk, email: simonovatn@yandex.ru

Gontar Elena S. - Ph.D. (chemistry), researcher, department of analytical chemistry, Donetsk National University, Donetsk 